\title{
MộT SỐ YẾU TỐ LIÊN QUAN CỦA TRẺ DƯớI 5 TUỔI VớI THIẾU HỤT VITAMIN D TẠI HUYỆN AN LÃO, HẢI PHÒNG NĂM 2016
}

\section{TÓM TẮT.}

Mục tiêu. Nghiên cứu nhằm xác định yễu tố liên quan giữa thiếu hụt vitamin $D$ và bệnh nhiễm khuẩn hô hấp cấp ở trẻ dưới 5 tuổi tại huyện An Lão, năm 2016. Đối tượng và phương pháp nghiên cứu. Đối tượng gồm 406 cặp bà mê/trẻ. Phương pháp nghiên cứu mố tả cắt ngang. Kết quả. Trên mô hình phân tích đa biến các yếu tố liên quan với thiếu hụt vitamin $\mathrm{D}$ gồm trẻ mắc nhiễm khuẩn hô hấp cấp $(\mathrm{OR}=2,65)$, trẻ đẻ dưới 37 tuần $(O R=1,74)$ và kinh tế mẹ nghèo hay dưới trung bình $(O R=2,27)$. Kết luận. Nhiễm khuẩn hô hấp cấp và thiếu hụt vitamin $D$ có mối liên quan chặt chẽ và độc lập với nhau. Cần có bổ sung thiếu hụt vitamin $D$ để cải thiện tình trạng nhiễm khuẩn hồ hấp cấp ở trẻ em dưới 5 tuổi

Tư khóa. Nhiễm khuẩn hô hấp cấp, thiếu hut vitamin D, Trẻ dưới 5 tuổi, Yếu tố liên quan, huyện An Lão.

\section{SUMMARY}

\section{SOME ASSOCIATED FACTORS IN CHILDREN UNDER FIVES WITH DEFICIENT/INSUFFICIENT VITAMIN D IN AN LAO, HAI PHONG IN 2016}

Objective. The study was well done to estimate some associated factors between deficient/insufficient vitamin $D$ and acute respiratory infection in children under 5 in An Lao, Hai Phong in 2016. Subjects and Methods. Subjects included 406 pairs of children and their mother. Method was a cross-sectional study. Results. In the final model of multivariate regression, some asscociated factors with vitamin D deficiency included acute respiratory infection $(\mathrm{OR}=2.65)$, gestational age at birth less than 37 weeks $(\mathrm{OR}=1.74)$, and maternal poverty or under average income $(\mathrm{OR}=2.27)$. Conclusions. Acute respiratory infection was an indepentent factor associated with vitamin D deficiency. It needs to supplement vitamin D for children under 5 to reduce the incidence of acute respiratory infection.

Keywords. Acute respiratory infection, An Lao District, Associated factors, Children under 5, Vitamin $\mathrm{D}$ deficiency.

\section{I. ĐẶT VẤN ĐỀ}

Nhiễm khuẩn hô hấp cấp là một nhóm bệnh do vi khuẩn hoặc virus gây nên những tổn thương viêm cấp tính ở một phần hay toàn bộ hệ

*Bệnh viện Trẻ em Hải Phòng

**Trường Đai hoc Y Dước Hải Phòng

Chịu trách nhiệm chính: Nguyễn Thị Ngọc Yến

Email: bsyenbvte@gmail.com

Ngày nhận bài: 15.6.2021

Ngày phản biên khoa hoc: 9.8.2021

Ngày duyệt bài: 16.8 .2021 thống đường hô hấp kể từ tai, mũi, họng cho đến phổi, màng phổi. Bệnh là không nhứng phổ biến mà còn là nguyên nhân gây tử vong hàng đầu ở trẻ dưới 5 tuổi. Theo Tổ chức $Y$ tế Thế giới (1990), hàng năm thế giới có khoảng 14 triệu trẻ em dưới 5 tuổi chết ( $95 \%$ ở các nước đang phát triển), trong đó có 4 triệu trẻ chết vì nhiễm khuẩn hô hấp cấp tính [3].

Từ năm 1983 Tổ chức Y tế Thế giới đã xây dựng chương trình phòng chống nhiễm khuẩn hô hấp cấp tính (chương trình ARI), áp dụng ở Việt Nam vào năm 1984 đã là làm tỷ lê mắc và tử vong đáng kể bệnh này tuy nhiên NKHHC vẫn là bệnh có tỷ lệ mắc và tử vong cao ở lứa tuổi này [3]. Indonesia, Ấn Độ, Nigeria, Pakistan và Trung Quốc đã chiếm 54\% trong số 138 triêu viêm phổi trên toàn cầu vào năm 2015 [8]. Theo Adebola E. Orimadegun và CS [4], có 1.071 triêu trẻ 1-59 tháng ở châu Phi chết vì viêm phổi, chiếm 14,1\% tử vong do tất cả các nguyên nhân.

Từ năm 2007, Holick FM [9] nhận thấy vai trò quan trọng của vitamin $D$ chống lại các bệnh nhiễm khuẩn trong đó có nhiễm khuẩn hô hấp cấp. Cụ thể nghiên cứu của Adrian R Martineau và $\operatorname{CS}[5]$ cho thấy vitamin $D$ có vai trò quan trọng trong việc làm giảm mức độ nặng, tử vong và tỷ lệ mắc NKHHC. Từ thực tể này, chúng tôi tiến hành đề tài nhằm xác định yếu tố liên quan giữa thiếu hụt vitamin $D$ và bệnh nhiễm khuẩn hô hấp cấp, là cơ sở để tiến hành nghiên cứu can thiệp. Nghiên cứu nhằm mục tiêu sau:

Mô tả một số yêu tố liên quan với thiếu hưt Vitamin $D$ ở trẻ dưới 5 tuổi tại huyện An Lão, thành phố Hải Phòng năm 2016.

\section{II. ĐỐl TƯỚNG VÀ PHƯƠNG PHÁP NGHIÊN CỨU}

2.1. Đối tượng, đia điểm và thời gian nghiên cứu. Gồm 406 cặp bà mẹ/trẻ dưới 5 tuổi.

Tiêu chuấn lựa chọn: trẻ trong độ tuổi, sống ở địa điểm nghiên cứu, không bị mắc các bênh bẩm sinh về tiêu hóa, tim mạch, thần kinh, xương cơ khớp. Bà me không mắc các bệnh tâm thần, câm điếc có khả năng trả lời câu hỏi của điều tra viên. Bà me đồng ý tham gia nghiên cứu.

Tiêu chuẩn loai: trẻ sử dụng vitamin $D$, uống polivitamin có chứa vitamin $D$ trong vòng 2 tuần đến ngày điều tra, mắc các bệnh rối loạn chuyển hóa ống thận, bệnh tuyến giáp.

Địa điểm nghiên cứu là Xã Trường Thọ và An 
Thắng của huyện An Lão. Thời gian nghiên cứu tháng 12 năm 2016.

\subsection{Phương pháp nghiên cứu}

2.2.1. Phương pháp nghiên cứu: Mô tả cắt ngang

2.2.2. Cỡ mẫu: Dựa vào công thức chọn mẫu thông qua tỷ lệ thiếu hụt vitamin $D_{\text {của }}$ nghiên cứu trước chúng tôi tính được cõ̃ mẫu là 406 cặp trẻ và bà mẹ. Mỗi xã nghiên cứu về lý thuyết 203 cặp trẻ/bà mẹ.

2.2.3. Quá trình chọn mẫu. Chọn mẫu theo phương pháp nhiều giai đoạn. Giai đoạn 1 chủ động chọn huyện An Lão, giai đoạn 2 chọn ngẫu nhiên xã Trường thọ và An Thắng trong 15 xã và 2 thị trấn của huyện An Lão. Chọn đối tượng và nghiên cứu theo phương pháp ngẫu nhiên hệ thống từ 1.345 trẻ dưới 5 tuổi.

2.2.4. Chỉ số và biến số

- Tuổi, giới của trẻ

- Cân nặng (Kg)

- Nồng độ vitamin D

- Tỷ lệ mắc ít nhất 1 bệnh nhiễm khuẩn trong vòng 4 tuần tính từ trước đến ngày điều tra

- Suy dinh dưỡng thấp còi (có/không)

- Trẻ đẻ nhẹ cân (có/không), trẻ đẻ thiếu tháng (có/không)

- Trẻ ăn sữa công thức/không được bú mẹ hoàn toàn 6 tháng đầu (có/không)

- Trẻ là con thứ nhất so với con thứ 2 và hơn (có/không)

- Trẻ không được tiêm chủng/tiêm chủng không đây đủ ở thời điểm điều tra ngang (có/không)

- Mẹ/người chăm sóc trẻ chính (là người thường xuyên cho trẻ ăn hàng ngày)

- Không được tắm nắng 6 giờ/tuần so với trên (có/không)

- Gia đình có kinh tế trung bình và nghèo so với trên (có/không)

- Học vấn mẹ tiểu học và dưới so với trên (có/khồng)

- Nghề mẹ làm ruộng so với nghề khác (có/không)

\subsubsection{Thu thập thông tin}

Thu thập thông tin gồm:

- Cân, đo trẻ

- Lấy máu làm xét nghiệm nồng độ vitamin $D$

- Khám toàn diện để phát hiện trè mắc nhiễm khuẩn hô hấp cấp

- Phỏng vấn bà mẹ về một số yếu tố liên quan với thiếu hụt vitamin $D$

2.2.6. Phân tích số liệu. Số liệu được nhập và phân tích nhờ phần mềm SPSS 20.0.
Tính tỷ lệ \%, phân tích đơn biến và đa biến. Tính OR

- Nếu OR=1 không có mối liên quan

- Nếu OR<1 có liên quan nghịch

- Nếu $\mathrm{OR}>1$, nằm trong $95 \% \mathrm{CI}$ và cực dưới của $95 \%$ CI cũng phải lớn hơn 1 thì có mối liên quan thuận.

\section{KẾT QUẢ NGHIÊN CỨU}

\subsection{Thông tin về đối tượng nghiên cứu}

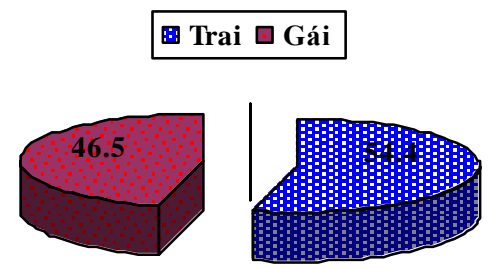

Hình 3.1. Phân bố đôî tượng nghiên cứu theo giới $(n=406)$

Có 221 trẻ trai tham gia nghiên cứu chiếm $54,4 \%$ và 185 trẻ gái tham gia nghiên cứu chiếm $45,6 \%$. Tỷ lệ trẻ trai cao hơn trẻ gái.

Bảng 3.1. Phân bố đối tượng theo nhóm tuổi

\begin{tabular}{|c|c|c|}
\hline $\begin{array}{c}\text { Nhóm tuối } \\
\text { (tháng) }\end{array}$ & Số lượng (n) & Tỷ lệ (\%) \\
\hline $0-<12$ & 13 & 3,2 \\
\hline $12-<24$ & 92 & 22,7 \\
\hline $24-<36$ & 107 & 26,4 \\
\hline $36-<48$ & 111 & 27,3 \\
\hline $48-<60$ & 83 & 20,4 \\
\hline Tống số & $\mathbf{4 0 6}$ & $\mathbf{1 0 0 , 0}$ \\
\hline
\end{tabular}

Nhân xét. Nhóm 24-<36 và 36-<48 tháng tuổi có tỷ lệ đối tượng tham gian nghiên cứu nhiều nhất tỷ lệ lần lượt là $26,4 \%$ và $27,3 \%$. Nhóm <12 tháng có tỷ iệ bệnh đối tượng tham gia thấp nhất là 3,2\%.

Bảng 3.2. Tý lệ thiêu vitamin D

\begin{tabular}{|c|c|c|}
\hline $\begin{array}{l}\text { Tỷ lệ thiếu } \\
\text { vitamin D }\end{array}$ & $\begin{array}{c}\text { Số lượng } \\
\text { (n) }\end{array}$ & $\begin{array}{l}\text { Tỷ lệ } \\
(\%)\end{array}$ \\
\hline $\begin{array}{l}\geq 30 \mathrm{ng} / \mathrm{mL} \\
\text { (bình thường) }\end{array}$ & 168 & 41,4 \\
\hline $\begin{array}{c}20-<30 \mathrm{ng} / \mathrm{mL} \\
\text { (thiếu vừa) }\end{array}$ & 229 & 56,4 \\
\hline $\begin{array}{l}<20 \mathrm{ng} / \mathrm{mL} \\
\text { (thiếu nặng) }\end{array}$ & 9 & 2,2 \\
\hline Tống số & 406 & 100,0 \\
\hline
\end{tabular}

Nhận xét. Tỷ lệ thiếu vừa là (hụt) $56,4 \%$, thiếu nặng (thiếu) $2,2 \%$, tỷ lệ thiếu chung là $58,6 \%$. 
Bảng 3.3. Kết quả phân tích đa biến yêu tố từ phía trẻ

\begin{tabular}{|c|c|c|c|c|}
\hline Yếu tố liên quan & $\begin{array}{l}\text { Thiếu } \\
\text { vitamin } \\
\text { D (n) }\end{array}$ & $\begin{array}{l}\text { Không } \\
\text { thiếu } \\
\text { (n) }\end{array}$ & $\begin{array}{l}\text { OR, } 95 \% C I, p \\
\text { phân tích đơn } \\
\text { biến }\end{array}$ & $\begin{array}{c}\text { OR, } 95 \% C I, p \\
\text { phân tích đa } \\
\text { biến }\end{array}$ \\
\hline $\begin{array}{c}\text { Tiêm phòng không đây } \\
\text { đủ/không tiêm }\end{array}$ & 133 & 66 & \multirow{2}{*}{$\begin{array}{c}1,96 \\
(1,31-2,92) \\
0,001\end{array}$} & \multirow{2}{*}{$\begin{array}{c}1,44 \\
(0,93-2,22) \\
0,099\end{array}$} \\
\hline Đầy đủ & 105 & 102 & & \\
\hline Không tắm nắng & 195 & 120 & \multirow{2}{*}{$\begin{array}{c}1,81(1,13-2,9) \\
0,012\end{array}$} & \multirow{2}{*}{$\begin{array}{c}1,38(0,84-2,28) \\
0,203\end{array}$} \\
\hline Có & 43 & 48 & & \\
\hline Sữa công thức/bú không đây đủ & 39 & 16 & \multirow{2}{*}{$\begin{array}{c}1,86(1,003-3,56) \\
0,047\end{array}$} & \multirow{2}{*}{$\begin{array}{c}1,39(0,72-2,71) \\
0,324\end{array}$} \\
\hline Bú mẹ hoàn toàn & 119 & 152 & & \\
\hline Cân khi sinh $<2500 \mathrm{~g}$ & 35 & 11 & \multirow{2}{*}{$\begin{array}{c}2,46(1,21-4,99) \\
0,11\end{array}$} & \multirow{2}{*}{$\begin{array}{c}2,03(0,95-4,33) \\
0,067\end{array}$} \\
\hline$\geq 2500 \mathrm{~g}$ & 203 & 157 & & \\
\hline Tuối thai<37 tuân & 89 & 39 & \multirow{2}{*}{$\begin{array}{c}1,96(1,26-3,08) \\
0,002\end{array}$} & \multirow{2}{*}{$\begin{array}{c}1,74(1,08-2,79) \\
0,022\end{array}$} \\
\hline$\geq 37$ tuần & 149 & 126 & & \\
\hline Nhiểm khuấn hô hấp & 112 & 37 & \multirow{2}{*}{$\begin{array}{c}3,15(2,017-4,91) \\
0,000\end{array}$} & \multirow{2}{*}{$\begin{array}{c}2,65(1,66-4,25) \\
0,000\end{array}$} \\
\hline Không & 126 & 131 & & \\
\hline SDD nhe cân & & & & \\
\hline Có & 37 & 10 & \multirow{2}{*}{$\begin{array}{c}2,91(1,4-6,03) \\
0,03\end{array}$} & \multirow{2}{*}{$2,11(0,97-4,57)$} \\
\hline Không & 201 & 158 & & \\
\hline
\end{tabular}

Nhận xét. Trên mô hình cuối cùng phân tích đa biến chúng tôi nhận thấy trong số 7 yếu tố có liên quan có ý nghĩa thống kê với thiếu vitamin $D$ ở phân tích đơn biến thì chỉ còn lại 2 yếu tố còn liên quan có ý nghĩa thống kê với thiếu vitamin D đó là: trẻ mắc NKHH và tuổi thai khi sinh dưới 37 tuần. Xét về sự thay đổi của $O R$ từ phân tích đơn biến sang đa biến chúng tôi thấy đối với yếu tố $\mathrm{NKHH}$ OR từ 3,15 còn 2,65 và yếu tố tuổi thai $\mathrm{OR}$ từ 1,96 xuống 1,74 .

Bảng 3.4. Kêt quá phân tích đa biến yêu tố từ phía mẹ

\begin{tabular}{|c|c|c|c|c|}
\hline Yếu tố liên quan & $\begin{array}{l}\text { Thiếu } \\
\text { vitamin } \\
\text { D (n) }\end{array}$ & $\begin{array}{l}\text { Không } \\
\text { thiếu } \\
\text { (n) }\end{array}$ & $\begin{array}{l}\text { OR, } 95 \% \text { \% }, p \\
\text { phân tích đơnn } \\
\text { biến }\end{array}$ & $\begin{array}{c}\text { OR, } 95 \% C I, p \\
\text { phân tích đa } \\
\text { biến }\end{array}$ \\
\hline Bình thường và nghèo & 202 & 119 & $2,31(1,42-3,56)$ & $2,27(1,38-3,71)$ \\
\hline Trên bình thường & 36 & 49 & 0,001 & 0,001 \\
\hline Tiểu học và dưới & 228 & 152 & $2,4(1,06-5,43)$ & $2,22(0,95-5,18)$ \\
\hline THCS và trên & 10 & 16 & 0,031 & 0,066 \\
\hline Nông dân & 132 & 119 & $1,51(1,013-2,24)$ & $1,29(0,85-1,95)$ \\
\hline Nghề khác & 36 & 49 & 0,042 & 0,24 \\
\hline
\end{tabular}

Nhận xét. Trên mô hình phân tích các yếu tố mẹ, chúng tôi nhận thấy thiếu vitamin $D$ chỉ còn liên quan đến kinh tế mẹ trung bình và dưới trung bình $O R$ đơn biến là 0,31 và $O R$ phân tích đa biến là 2,27.

\section{BÀN LUÂNN}

Sau đây chúng tôi có một số bàn luận về yếu tố liên quan có ý nghĩa thống kê ở mổ hình hồi quy đa biến cuối cùng.

4.1. Yếu tố từ phía trẻ. Bảng 3.3 khảo sát liên quan tuổi thai với thiếu vitamin $D$ kết quả cho thấy đối tượng có tiền sử tuổi thai dưới 37 tuần thì nguy cơ thiếu vitamin $D$ tăng lên 1,74 lần với 95\%CI từ 1,08 đến 2,79.

Kết quả nghiên cứu của chúng tôi phù hợp với kết quả nghiên cứu của Nguyển Xuân Hùng [2]. Trè sinh nhe cân $(<2500 \mathrm{~g})$ nguy cơ thiếu hụt vitamin $D$ giảm đi 0,82 lần nhưng tác giả không thây có liên quan giữa thiếu vitamin $D$ với tuổi thai khi sinh thấp dưới 37 tuần.
Vicka Oktaria và CS [12] nghiên cứu thiếu hụt vitamin $D$ và viêm phổi năng ở trẻ em Indonesia năm 2021, cho thấy thiếu vitamin D liên quan chặt chẽ với trẻ nhẹ cân, suy dinh dưỡng nhưng lại không liên quan đến triệu chứng nặng, thời gian nằm viện và mức độ bão hòa oxi của trè.

Theo Đặng Văn Chức [1] trẻ đẻ nhẹ cân thiếu tháng thường hay mắc bệnh nhiễm khuẩn làm tăng tiêu thụ vitamin $D$. Trẻ đẻ nhe cân thiếu tháng bú kém do đó thiếu nguồn vitamin $D$ từ sữa mẹ. Trẻ đẻ nhe cân thiếu tháng da thường vàng do tăng bilirubin tự do làm cản trở tổng hợp vitamin $D$ nên cũng hay thiếu vitamin $D$.

Trẻ nhiễm khuẩn hô hấp nguy cơ thiếu vitamin $D$ tăng lên 2,65 lần so với trẻ không mắc 
nhiễm khuẩn hô hấp.

Gần đây các nhà khoa học đã phát hiện ra vai trò của Vitamin $\mathrm{D}$ trong miễn dịch, giúp cho người ta ít mắc các bệnh nhiễm khuẩn. Nghiên cứu của Chowdhury R và CS [7] ở Ấn Đố cho thấy trong số 960 trẻ được nghiên cứu có 331 chiếm 34,5\% trẻ thiếu Vitamin D. Sau khi phân tích đa biến với các yếu tố tuổi, giới, tình trạng nuôi bằng sữa mẹ, SDD nhẹ cân, thấp còi và gầy mòn, các tác giả nhận thấy thiếu Vitamin $D$ còn liên quan chặt chẽ với nhiểm khuẩn hô hấp và có quan hê qua lai. Thiếu Vitamin $D$ trẻ dễ nhiễm khuẩn hô hấp và khi nhiễm khuẩn hô hấp cấp trẻ lại càng thiếu Vitamin D. Zhaojun Chen và CS [13] nghiên cứu thực trạng thiếu hụt vitamin $D$ ở trẻ em tiền học đường vùng Hangzhou, Trung Quốc thấy thiếu hut vitamin D liên quan đến bệnh nhiễm khuẩn. Cụ thể số lần sâu răng tăng lên 0,08 lần $/ 1 \mathrm{ng} / \mathrm{ml}$ vitamin $D$ giảm đi. Balsam Quabais Saeed và CS [6] nghiên cứu tỷ lê thiếu hụt vitamin $D$ và yếu tố liên quan với nhiếm khuẩn hô hấp cho thây thiếu hụt vitamin $\mathrm{D}$ liên quan mạnh với bệnh viêm amidal ở đối tượng nghiên cứu.

4.2. Yếu tố từ phía mẹ. Kinh tế mẹ thấp, thu nhập kém me phải tăng thời gian làm việc để tăng thêm thu nhập cho gia đình do vậy không có thời gian chăm sóc con hoặc để người khác như ông bà, anh chị chăm sóc do đó trẻ hay "ốm". Trẻ đã thiếu nguồn vitamin D tổng hợp qua da do phải ở trẻ trong nhà lại thiếu nguồn vitamin $\mathrm{D}$ từ thức ăn do đó càng làm trầm trọng thêm tình trạng thiếu hụt vitamin $D$.

Nhận xét của chúng tôi cũng phù hợp với nhận xét của Jabulani $R$ Ncayiyana và CS [10]. Khi khảo sát yếu tố liên quan với thiếu hụt vitamin $\mathrm{D}$ tác giả nhận thấy nơi ở, điều kiện kinh tế xã hội thấp, giới tính của trẻ, mùa đông, trẻ được nuôi bằng sữa me hay đang bú me có nguy cơ cao thiếu vitamin D. Swathi Chacham và CS [11] nhận thấy thiếu hụt vitamin $D$ hay gặp ở trẻ sơ sinh, me thiếu vitamin $D$ và gia đình có điều kiện kinh tể thấp kém.

\section{KẾT LUÂ̂N}

Trên mồ hình phân tích đa biến các yếu tố liên quan với thiếu hụt vitamin $D$ gồm trẻ mắc nhiễm khuẩn hô hấp cấp $(\mathrm{OR}=2,65)$, trẻ đẻ dưới 37 tuần $(O R=1,74)$ và kinh tế mẹ nghèo và dưới trung bình $(\mathrm{OR}=2,27$.

Nhiễm khuẩn hô hấp cấp và thiếu hụt vitamin $D$ có mối liên quan chặt chẽ và độc lập với nhau. Cần có bổ sung thiếu hụt vitamin $D$ để cải thiện tình trạng nhiễm khuẩn hô hấp cấp ở trẻ em dưới 5 tuổi

\section{TÀI LIẸU THAM KHẢO}

1. Đăng Văn Chức (2020), Trẻ đẻ nhẹ cân, Giáo trình Nhi khoa sau đại học, Nhà xuất bản $Y$ học, trang 58-63.

2. Nguyển Xuân Hùng (2020), Thực trang suy dinh dưỡng thấp còi và hiệu quả can thiệp ở trẻ 12 đến 36 tháng tuổi tai huyên Kim Đông, tỉnh Hưng Yên năm 2017", Luận án tiến sỹ Y học, Trường đại học Y Dược Hải Phòng.

3. Trần Quy. (2013), "Nhiễm khuẩn hô hấp cấp tính", Bài giảng nhi khoa tập 1 - Nhà xuất bản y học Hà Nội, trang 380-389.

4. Adebola E. Orimadegun et al (2020), "A systematic review and meta-analysis of sex defferences in morbidity and mortality of acute lower respiratory tract infections among african children", J Pediatr Rev, 8(2):65-78. doi:10.32598/jpr.8.2.65.

5. Adrian R Martineau et al (2017), "Vitamin D supplementation to prevent acute respiratory tract infections : systematic review and meta-analysis of individual participant data", BMJ 356:i6583, doi:10.1136/bmj.i6583.

6. Balsam Qubais Saeed et al (2021), "Vitamin D deficiency and insufficiency among university students: prevalence, risk factors, and the associattion between vitamin $\mathrm{D}$ deficiency and episodes of respiratory tract infections", Risk manag Healthc Policy, 14:2733-2744, doi:10.2147/RMHP.S308754.

7. Chowdhury R et al (2017), "Vitamin D dificiecy predicts infections in young north Indian children: a secondary data analysis", Plos One, 8;12(3):e0170509.

8. David A McAllister et al (2019), "Global, regional, and national estimates of pneumonia morbidity and mortality in children younger than 5 years between 2000 and 2015: a systematic analysis", Lancet Glob Health, 7(1):e47e57.doi:10.1016/S2214-109X(18)304408-X.

9. Holick MF and Tai C Chen (2008), "Vitamin D deficiency: a worldwide problem with health consequences", Am J Clin Nutr. 87 (4): 1080S $1086 \mathrm{~S}$

10. Jabulani R. Ncayiyana et al (2021), "Prevalence and correlates of vitamin D deficiency among Young South Africa Infants: A birth cohort study", Nutrients, 13(5): 1500, doi: 10. 3390/nu13051500.

11. Swathi Chacham et al (2020), "Prevalence of vitamin $D$ deficiency among infants in Northern India: a hospital based prospective study", Cureus, 12(11): e11353, doi: 10.7759/cureus.11353.

12. Vicka Oktaria et al (2021), "Vitamin D deficiency and severity of pneumonia in Indonesian children", PloS One, 16(7):e0254488, doi:10.1371/journal.pone.0254488.

13. Zhaojun Chen et al (2021), "Vitamin D status and its influence on the health of preschool children in Hangzhou", Front Public Health, 9:675403, doi: 10.3389/fpbh.2021.675403. 